\title{
Some New Concepts of Continuity in Generalized Topological Space
}

\author{
P. L. Powar \\ Professor \\ Department of Mathematics and Computer Science \\ Rani Durgawati University, Jabalpur, India
}

\author{
K. L. Rajak \\ Department of Mathematics and Computer Science \\ Rani Durgawati University, Jabalpur, India
}

\begin{abstract}
In the present paper, we have studied the analogue of some continuous functions in generalized topological space and consequently their behavior in fine topological space (cf. [18]).
\end{abstract}

\section{KEYWORDS}

Fine-open sets, g-open sets, g- $\alpha$-open sets, g- $\beta$-open sets, gsemi-open sets, g-pre-open sets.

\section{AMS SUBJECT CLASSIFICATION}

Primary - 54XX, Secondary- 54CXX.

\section{INTRODUCTION}

The idea of fine space has been initiated by Powar and Rajak in [18]. In view of the definition of generalized topological space [8] it has been noticed that the fine space is a special case of generalized topological space (cf. [8]). Zorlutuna [20] has initiated a class of different generalized continuous functions by considering the concepts of regular open sets, clopen sets, etc. In the present paper, we have defined these sets in the generalized topological space and studied the analogue of continuous functions due to Zorlutuna [20] in the generalized topological space.

Our aim in this paper, is to define a new mapping viz. completely fine-irresolute. We have noticed that, some of the continuous functions which are studied in generalized topological space are clubbed into a single fine-irresolute function (see [18], [19]) and the remaining are incorporated into completely fine-irresolute map.

\section{PREREQUISTICES}

We need the following concepts for our study.

(1) $\mathrm{p}:(\mathrm{X}, \tau) \rightarrow\left(\mathrm{Y}, \tau^{\prime}\right)$ denotes a single valued function from a topological space $(\mathrm{X}, \tau)$ to a topological space $\left(\mathrm{Y}, \tau^{\prime}\right)$.

(2) $\mathrm{q}:(\mathrm{X}, \mathrm{gx}) \rightarrow\left(\mathrm{X}^{\prime}, \mathrm{gx}^{\prime}\right)$ denotes a single valued function from a generalized topological space $(X, \mathrm{gx})$ to a generalized topological space $\left(\mathrm{X}^{\prime}, \mathrm{gx}^{\prime}\right)$.

(3) $\mathrm{r}:\left(\mathrm{X}, \tau_{\mathrm{f}}\right) \rightarrow\left(\mathrm{Y}, \tau_{\mathrm{f}}{ }^{\prime}\right)$ denotes a single valued function from a fine space $\left(\mathrm{X}, \tau_{\mathrm{f}}\right)$ to a fine space $\left(\mathrm{Y}, \tau_{\mathrm{f}}\right)$.

For our analysis, we require the following basic definitions.

2.1 Definition A subset $S$ of a topological space (X, $\tau$ ) is called

(a) $\alpha$-open [4] if $S \subseteq \operatorname{Int}(\operatorname{cl}(\operatorname{Int}(S)))$ (b) semi-open [4] if $\mathrm{S} \subseteq \operatorname{cl}(\operatorname{Int}(\mathrm{S}))$

(c) pre-open [4] if $\mathrm{S} \subseteq \operatorname{Int}(\operatorname{cl}(\mathrm{S}))$

(d) $\beta$-open [4] if $S \subseteq \operatorname{cl}(\operatorname{Int}(\operatorname{cl}(S)))$

(e) regular-open [4] if $\mathrm{S}=\operatorname{Int}(\operatorname{cl}(\mathrm{S}))$

(f) clopen if $\mathrm{S}$ is both open and closed.

2.2 Definition Let $X$ be a nonempty set and $g$ be a collection of subsets of $X$. Then $g$ is called a generalized topology on $\mathrm{X}$ if $\phi \in \mathrm{g}$ and $\mathrm{G}_{\mathrm{i}} \in \mathrm{g}$ for $\mathrm{i} \in \mathrm{I} \neq \phi$ implies $\mathrm{G}=$ $\mathrm{U}_{\{i \in I\}} G_{i} \in g$. We say $\mathrm{g}$ is strong if $\mathrm{X} \in \mathrm{g}$, and we call the pair (X, gx) a generalized topological space on $X$ (cf. [8]).

2.3 Remark The elements of $g$ are called g-open sets and their complements are called g-closed sets.

2.4 Definition Let $A \subseteq X$, then the generalized closure of $\mathrm{A}$ is defined by the intersection of all g-closed sets containing A and is denoted by $\mathrm{c}_{\mathrm{g}}(\mathrm{A})$ (cf. [8]).

2.5 Definition Let $\mathrm{A} \subseteq \mathrm{X}$, then the generalized interior of $\mathrm{A}$ is defined by the union of all g-open sets contained in $\mathrm{A}$ and is denoted by $\mathrm{i}_{\mathrm{g}}(\mathrm{A})$. A) (cf. [8]).

Then, we have $i_{g}(A)=C-c_{g}(X-A)$ and $c_{g}(A)=X-i_{g}(X-$

2.6 Definition Let $(X, \mathrm{gx})$ be a generalized topological space and $A \subseteq X$. Then, $A$ is said to be

(a) g-semi-open [9] if $\mathrm{A} \subseteq \mathrm{c}_{\mathrm{g}}\left(\mathrm{i}_{\mathrm{g}}(\mathrm{A})\right)$

(b) g-pre-open [9] if $\mathrm{A} \subseteq \mathrm{i}_{\mathrm{g}}\left(\mathrm{c}_{\mathrm{g}}(\mathrm{A})\right)$

(c) g- $\alpha$-open [9] if $A \subseteq \mathrm{i}_{\mathrm{g}}\left(\mathrm{c}_{\mathrm{g}}\left(\mathrm{i}_{\mathrm{g}}(\mathrm{A})\right)\right)$

(d) g- $\beta$-open [9] if $\mathrm{A} \subseteq \mathrm{c}_{\mathrm{g}}\left(\mathrm{i}_{\mathrm{g}}\left(\mathrm{c}_{\mathrm{g}}(\mathrm{A})\right)\right)$

(e) g-r-open [13] if $\mathrm{A}=\mathrm{i}_{\mathrm{g}}\left(\mathrm{c}_{\mathrm{g}}(\mathrm{A})\right.$

(f) g- clopen if A is both g- open and g-closed.

The complement of a g-semi-open (resp. g-pre open, g- $\alpha$-open, $\mathrm{g}$ - $\beta$-open) set is called g-semi-closed (resp. $\mathrm{g}$ pre-closed, g- $\alpha$-closed, g- $\beta$-closed) set. We denote by $\sigma(\mathrm{g})$, (resp. $\mathrm{p}(\mathrm{g}), \alpha(\mathrm{g}), \beta(\mathrm{g}))$ the class of all g-semi-open sets (resp. g-pre -open, g- $\alpha$-open, g- $\beta$-open).

2.7 Remark In view of Definition 2.5, it may be noted that the following inclusions hold:

(1) $\mathrm{g} \subseteq \alpha(\mathrm{g}) \subseteq \sigma(\mathrm{g}) \subseteq \beta(\mathrm{g})$,

(2) $\alpha(\mathrm{g}) \subseteq \mathrm{p}(\mathrm{g}) \subseteq \beta(\mathrm{g})$. 
(3) Every g-clopen set is gr-open set.

2.8 Definition Let $(X, \tau)$ be a topological space, we define

$\tau\left(\mathrm{A}_{\alpha}\right)=\tau_{\alpha}$ (say) $=\left\{\mathrm{G}_{\alpha}(\neq \mathrm{X}): \mathrm{G}_{\alpha} \cap \mathrm{A}_{\alpha} \neq \emptyset\right.$, for $\mathrm{A}_{\alpha} \in \tau$ and $\mathrm{A}_{\alpha} \neq$ $\emptyset$

set. $\}$

$$
\mathrm{X} \text {, for some } \alpha \in \mathrm{J} \text {, where } \mathrm{J} \text { is the index }
$$

Now, we define

$$
\tau_{\mathrm{f}}=\left\{\emptyset, \mathrm{X}, \mathrm{U}_{\alpha \in J}\left\{\tau_{\alpha}\right\}\right\}
$$

The above collection $\tau_{\mathrm{f}}$ of subsets of $\mathrm{X}$ is called the fine-collection of subsets of $X$ and $\left(X, \tau, \tau_{\mathrm{f}}\right)$ is said to be the fine-space of $X$, generated by the topology $\tau$ on X. (cf. [18] ).

2.9 Definition A subset $U$ of a fine space $X$ is said to be a fine-open set of $X$, if $U$ belongs to the collection $\tau_{f}$ and the complement of every fine-open set of $\mathrm{X}$ is called the fineclosed set of $\mathrm{X}$ and we denote the collection by $\mathrm{F}_{\mathrm{f}}$ (cf [18]).

2.10 Definition A function $\mathrm{f}:\left(\mathrm{X}, \tau_{\mathrm{f}}\right) \rightarrow\left(\mathrm{Y}, \tau_{f}^{\prime}\right)$ is called fine-irresolute (or f-irresolute) [18] if $\mathrm{f}^{-1}(\mathrm{~V})$ is fine-open in $\mathrm{X}$ for every fine-open set $\mathrm{V}$ of $\mathrm{Y}$.

2.11 Definition A subset $S$ of a fine-space $\left(X, \tau_{f}\right)$ is said to be fine-clopen (or f-clopen) [18] if $\mathrm{S}$ is both fine-open and fine-closed.

Notations: In view of Definition 2.4 and 2.5, we denote the generalized interior and generalized closure in a finespace by $f_{\text {int }}$ and $f_{c l}$, respectively.

2.12 Definition A subset $S$ of a fine-space $\left(X, \tau_{f}\right)$ is said to be fine-regular open (or fr-open) [18] if $S=f_{\text {int }} f_{c l}(S)$ ).

2.13 Definition A function $\mathrm{f}: \mathrm{X} \rightarrow \mathrm{Y}$ is called completely $\quad \beta$-irresolute $[20]$ if $\mathrm{f}^{-1}(\mathrm{~V})$ is regular open in $\mathrm{X}$ for every $\beta$-open set $\mathrm{V}$ of $\mathrm{Y}$.

2.14 Definition A function $\mathrm{f}: \mathrm{X} \rightarrow \mathrm{Y}$ is called completely continuous [3] (resp. R-map [6]) if $\mathrm{f}^{-1}(\mathrm{~V})$ is regular open in $\mathrm{X}$ for every open (resp. regular open) set $\mathrm{V}$ of Y.

2.15 Definition A function $\mathrm{f}: \mathrm{X} \rightarrow \mathrm{Y}$ is called $\beta$ irresolute [12] (resp. $\beta$-continuous [1]) if $\mathrm{f}^{-1}(\mathrm{~V})$ is $\beta$-open in $\mathrm{X}$ for every $\beta$-open (resp. open) set $\mathrm{V}$ of $\mathrm{Y}$.

2.16 Definition A function $\mathrm{f}: \mathrm{X} \rightarrow \mathrm{Y}$ is called $\beta$-open [1] if the image of every open subset of $X$ is $\beta$-open in $Y$.

2.17 Definition A function $\mathrm{f}: \mathrm{X} \rightarrow \mathrm{Y}$ is said to be perfectly $\beta$-irresolute [20] if $\mathrm{f}^{-1}(\mathrm{~V})$ is clopen in $X$ for every $\beta$ open set $\mathrm{V}$ of $\mathrm{Y}$.

2.18 Definition A function $\mathrm{f}: \mathrm{X} \rightarrow \mathrm{Y}$ is called perfectly continuous [17] if $f^{-1}(V)$ is clopen in $X$ for every open set $V$ of $\mathrm{Y}$.

2.19 Definition A function $\mathrm{f}: \mathrm{X} \rightarrow \mathrm{Y}$ is said to be perfectly irresolute [20] if $f^{-1}(V)$ is clopen in $X$ for every semi-open set $\mathrm{V}$ of $\mathrm{Y}$.

2.20 Definition A function $\mathrm{f}: \mathrm{X} \rightarrow \mathrm{Y}$ is called irresolute [7] (resp. semi-continuous [10]) if $\mathrm{f}^{-1}(\mathrm{~V})$ is semi-open in $X$ for every semi-open (resp. open) set V of Y.
2.21 Definition A function $\mathrm{f}: \mathrm{X} \rightarrow \mathrm{Y}$ is called semiopen [5] if the image of every open subset of $X$ is semi-open in Y.

2.22 Definition A function $\mathrm{f}: \mathrm{X} \rightarrow \mathrm{Y}$ is called

1. completely irresolute [16] if $\mathrm{f}^{-1}(\mathrm{~V})$ is regular open in $\mathrm{X}$ for every semi-open set $\mathrm{V}$ of $\mathrm{Y}$.

2. completely preirresolute $[15]$ if $f^{-1}(V)$ is regular open in $X$ for every preopen set $\mathrm{V}$ of $\mathrm{Y}$.

3. completely- $\alpha$-irresolute [16] if $\mathrm{f}^{-1}(\mathrm{~V})$ is regular open in $\mathrm{X}$ for every $\alpha$-open set $\mathrm{V}$ of $\mathrm{Y}$.

4. strongly $\beta$-irresolute [14] if $\mathrm{f}^{-1}(\mathrm{~V})$ is open in $\mathrm{X}$ for every $\beta$-open set $\mathrm{V}$ of $\mathrm{Y}$.

5. strongly M-precontinuous [2] if $f^{-1}(V)$ is open in $X$ for every preopen set $\mathrm{V}$ of $\mathrm{Y}$.

6. strongly $\alpha$-irresolute [11] if $\mathrm{f}^{-1}(\mathrm{~V})$ is open in $\mathrm{X}$ for every $\alpha$-open set $\mathrm{V}$ of $\mathrm{Y}$.

2.23 Definition A function $\mathrm{f}: \mathrm{X} \rightarrow \mathrm{Y}$ is called perfectly $\alpha$-irresolute [20] if $f^{-1}(V)$ is clopen in $X$ for every $\alpha$-open set $\mathrm{V}$ of $\mathrm{Y}$.

2.24 Remark It is interesting to note that in the fine space the class of fine-clopen sets is same as the class of fineregular sets.

\section{GENERALIZED COMPLETELY IRRESOLUTE FUNCTIONS IN g- TOPOLOGICAL SPACE}

Referring Definitions 2.13-2.23, in this section, we define there analogue in the generalized topological space.

3.1 Definition A function $\mathrm{q}:(\mathrm{X}, \mathrm{gx}) \rightarrow\left(\mathrm{X}^{\prime}, \mathrm{gx}^{\prime}\right)$ is called completely $g$ - $\beta$-irresolute if $q^{-1}(V)$ is gr-open in $X$ for every $g$ $\beta$-open set V of $X^{\prime}$.

3.2 Example Let $X=\{a, b, c\}$ with the generalized topology $\mathrm{gx}=\{\varnothing, \mathrm{X},\{\mathrm{c}\},\{\mathrm{a}, \mathrm{b}\},\{\mathrm{b}, \mathrm{c}\}\}$ and $\mathrm{X}^{\prime}=\{1,2,3\}$ with the generalized topology $\mathrm{gx}^{\prime}=\left\{\varnothing, X^{\prime},\{2\}\right\}$.

We define a mapping $\mathrm{q}:(\mathrm{X}, \mathrm{gx}) \rightarrow\left(\mathrm{X}^{\prime}, \mathrm{gx}^{\prime}\right)$ such that $q(a)=q(b)=2$ and $q(c)=3$. It can be easily checked that the only $g$ - $\beta$-open sets of $X^{\prime}$ are $\{2\},\{1,2\},\{2,3\}$ and their respective pre-images are $\{a, b\},\{a, b\}, X$, which are gr-open in $\mathrm{X}$. Therefore, $\mathrm{q}$ is completely $\mathrm{g}$ - $\beta$ - irresolute.

3.3 Definition A function $\mathrm{q}:(X, \mathrm{gx}) \rightarrow\left(\mathrm{X}^{\prime}, \mathrm{gx}^{\prime}\right)$ is called completely g-continuous if $\mathrm{q}^{-1}(\mathrm{~V})$ is gr-open in $\mathrm{X}$ for every $\mathrm{g}$ open set $\mathrm{V}$ of $\mathrm{X}^{\prime}$.

3.4 Example Let $X=\{1,2,3\}$ with the generalized topology $\operatorname{gx}=\{\varnothing,\{1\},\{2\},\{1,2\}\}$ and $X^{\prime}=\{a, b, c\}$ with the generalized topology $\mathrm{gx}^{\prime}=\{\emptyset,\{\mathrm{a}\}\}$.

We define a mapping q: $(\mathrm{X}, \mathrm{gx}) \rightarrow\left(\mathrm{X}^{\prime}, \mathrm{gx}^{\prime}\right)$ such that $q(1)=a, q(2)=b$ and $q(3)=c$. It can be easily checked that the only g-open sets of $X^{\prime}$ are $\{a\}, \phi$ and their respective preimages are $\{1\}, \phi$, which are gr-open in $X$. Hence, $q$ is completely g-continuous.

3.5 Definition A function $\mathrm{q}:(X, \mathrm{gx}) \rightarrow\left(\mathrm{X}^{\prime}, \mathrm{gx} \mathrm{X}^{\prime}\right)$ is called $\mathrm{g}$ - $\beta$-irresolute if $\mathrm{q}^{-1}(\mathrm{~V})$ is $\mathrm{g}$ - $\beta$-open in $X$ for every $\mathrm{g}$ - $\beta$-open set $\mathrm{V}$ of $\mathrm{X}^{\prime}$. 
3.6 Example Let $X=\{a, b, c\}$ with the generalized topology $\mathrm{gx}=\{\phi,\{\mathrm{a}, \mathrm{b}\}\}$ and $\mathrm{X}^{\prime}=\{1,2,3\}$ with the generalized topology $\mathrm{gx}^{\prime}=\{\phi, \mathrm{X},\{1,2\},\{2,3\}\}$.

We define a mapping q: $(X, g x) \rightarrow\left(X^{\prime}, \mathrm{gx}^{\prime}\right)$ such that $\mathrm{q}(\mathrm{a})=1, \mathrm{q}(\mathrm{b})=2$ and $\mathrm{q}(\mathrm{c})=3$. It may be checked that the g- $\beta$-open sets of $X^{\prime}$ are $\{1,2\},\{1,3\},\{2,3\},\{2\}$ and their respective pre-images are $\{a, b\},\{a, c\},\{b, c\},\{b\}$, which are $\mathrm{g}-\beta$-open in $\mathrm{X}$. Hence, $\mathrm{q}$ is $\mathrm{g}$ - $\beta$-irresolute.

3.7 Definition A function $\mathrm{q}:(X, \mathrm{gx}) \rightarrow\left(\mathrm{X}^{\prime}, \mathrm{gx}^{\prime}\right)$ is called $\mathrm{g}-\beta$-continuous if $\mathrm{q}^{-1}(\mathrm{~V})$ is $\mathrm{g}$ - $\beta$-open in $\mathrm{X}$ for every g-open set $\mathrm{V}$ of $\mathrm{X}^{\prime}$.

3.8 Example Let $X=\{1,2,3\}$ with the generalized topology $\mathrm{gx}=\{\phi, X,\{3\},\{1,2\},\{2,3\}\}$ and $X^{\prime}=\{a, b, c\}$ with the generalized topology $\mathrm{gx}^{\prime}=\{\phi, X,\{\mathrm{a}, \mathrm{b}\},\{\mathrm{b}, \mathrm{c}\}\}$.

We define a mapping q: $(X, g x) \rightarrow\left(X^{\prime}, g^{\prime}\right)$ such that $\mathrm{q}(1)=\mathrm{a}, \mathrm{q}(2)=\mathrm{b}$, and $\mathrm{q}(3)=\mathrm{c}$. It may be seen that the $\mathrm{g}-$ open sets of $\mathrm{X}^{\prime}$ are $\{a, b\},\{b, c\}$ and their respective preimages are $\{1,2\},\{2,3\}$, which are $g$ - $\beta$-open in $X$. Hence, $q$ is $\mathrm{g}$ - $\beta$-continuous.

3.9 Definition A function $\mathrm{q}:(X, \mathrm{gx}) \rightarrow\left(\mathrm{X}^{\prime}, \mathrm{gx} \mathrm{X}^{\prime}\right)$ is called g-R-map if $\mathrm{q}^{-1}(\mathrm{~V})$ is gr-open in $\mathrm{X}$ for every gr-open set $\mathrm{V}$ of $\mathrm{X}^{\prime}$.

3.10 Example Let $X=\{a, b, c\}$ with the generalized topology $g \mathrm{X}=\{\varnothing, \mathrm{X},\{\mathrm{a}, \mathrm{b}\},\{\mathrm{b}, \mathrm{c}\},\{\mathrm{c}\}\}$ and $\mathrm{X}^{\prime}=\{1,2,3\}$ with the generalized topology $\mathrm{gx}^{\prime}=\{\phi,\{2\},\{3\},\{2,3\}$.

We define a mapping $\mathrm{q}:(\mathrm{X}, \mathrm{gx}) \rightarrow\left(\mathrm{X}^{\prime}, \mathrm{gx} \mathrm{X}^{\prime}\right)$ such that $q(a)=q(b)=2$ and $q(c)=3$. It may be easily checked that the gr- open sets of $X^{\prime}$ are $\{2\},\{3\}$ and their respective preimages are $\{a, b\},\{c\}$, which are gr-open in X. Hence, $q$ is $g$ R- open map.

3.11 Definition A function $\mathrm{q}:(\mathrm{X}, \mathrm{gx}) \rightarrow\left(\mathrm{X}^{\prime}, \mathrm{gx}^{\prime}\right)$ is called $\mathrm{g}$ - $\beta$-open if the image of every g-open subset of $\mathrm{X}$ is $\mathrm{g}-\beta$-open in $\mathrm{X}^{\prime}$.

3.12 Example Let $X=\{1,2,3\}$ with the generalized topology $\mathrm{gx}=\{\varnothing,\{2,3\}\}$ and $\mathrm{X}^{\prime}=\{\mathrm{a}, \mathrm{b}, \mathrm{c}\}$ with the generalized topology $\mathrm{gx}^{\prime}=\left\{\varnothing, \mathrm{X}^{\prime},\{\mathrm{a}, \mathrm{b}\},\{\mathrm{b}, \mathrm{c}\}\right\}$.

We define a mapping q: $(X, g x) \rightarrow\left(X^{\prime}, g^{\prime}\right)$ such that $q(1)=a, q(2)=b$ and $q(3)=c$. It may be checked that the image of g-open sets $\{2,3\}, \varnothing$ of $X$ are $\{b, c\}, \varnothing$, which are g$\beta$ open in $X$. Hence, $q$ is $g-\beta$-open map.

3.13 Definition A function $\mathrm{q}:(\mathrm{X}, \mathrm{gx}) \rightarrow\left(\mathrm{X}^{\prime}, \mathrm{gx}^{\prime}\right)$ is called g-irresolute if $q^{-1}(V)$ is g-semi-open in $X$ for every gsemi-open set $\mathrm{V}$ of $\mathrm{X}^{\prime}$.

3.14 Example Let $X=\{a, b, c\}$ with the generalized topology $\mathrm{gx}=\{\varnothing, \mathrm{X},\{\mathrm{a}\},\{\mathrm{a}, \mathrm{b}\},\{\mathrm{b}, \mathrm{c}\}\}$ and $\mathrm{X}^{\prime}=\{1,2,3\}$ with the generalized topology $\mathrm{gx}^{\prime}=\left\{\varnothing, \mathrm{X}^{\prime},\{1,2\},\{2,3\}\right\}$.

We define a mapping q: $(X, g x) \rightarrow\left(X^{\prime}, g^{\prime}\right)$ such that $q(a)=1, q(b)=2$ and $q(c)=3$. It may be checked that the $g-$ semi open sets of $X^{\prime}$ are $\{1,2\},\{2,3\}, \emptyset, X^{\prime}$ and their respective pre-images are $\{a, b\},\{b, c\}, \emptyset, X$, which are gsemi-open in X. Hence, q is g-irresolute.

3.15 Definition A function $\mathrm{q}:(\mathrm{X}, \mathrm{gx}) \rightarrow\left(\mathrm{X}^{\prime}, \mathrm{gx}^{\prime}\right)$ is called g-semi-continuous if $q^{-1}(V)$ is g-semi-open in $X$ for every g- open set $\mathrm{V}$ of $\mathrm{X}^{\prime}$.
3.16 Example Let $X=\{a, b, c\}$ with the generalized topology $\operatorname{gx}=\{\varnothing,\{a\},\{b\},\{a, b\}\}$ and $X^{\prime}=\{1,2,3\}$ with the generalized topology $\mathrm{gx}^{\prime}=\{\varnothing,\{1,2\}\}$.

We define a mapping $\mathrm{q}:(\mathrm{X}, \mathrm{gx}) \rightarrow\left(\mathrm{X}^{\prime}, \mathrm{gx} \mathrm{X}^{\prime}\right)$ such that $q(a)=1, q(b)=2$ and $q(c)=3$. It may be checked that the g- open sets of $X^{\prime}$ are $\{1,2\}, \emptyset$ and their respective preimages are $\quad\{a, b\}, \varnothing$, which are $g$-semi -open in $X$. Hence, $\mathrm{q}$ is $\mathrm{g}$-semi-continuous.

3.17 Definition A function $\mathrm{q}:(\mathrm{X}, \mathrm{gx}) \rightarrow\left(\mathrm{X}^{\prime}, \mathrm{gx}^{\prime}\right)$ is called g-semi-open if the image of every g-open subset of $X$ is g- semi - open in $\mathrm{X}^{\prime}$.

3.18 Example Let $X=\{a, b, c\}$ with the generalized topology $\operatorname{gx}=\{\varnothing,\{b\}\}$ and $X^{\prime}=\{1,2,3\}$ with the generalized topology $\mathrm{gx}^{\prime}=\left\{\emptyset, \mathrm{X}^{\prime},\{1,2\},\{2,3\}\right\}$.

We define a mapping $\mathrm{q}:(\mathrm{X}, \mathrm{gx}) \rightarrow\left(\mathrm{X}^{\prime}, \mathrm{gx}^{\prime}\right)$ such that $q(a)=1, q(b)=2$ and $q(c)=3$. It may be seen that the only g- open sets of $X$ are $\{b\}, \varnothing$ and their respective images are $\{2\}, \emptyset$, which are g-semi-open in $X^{\prime}$, hence $q$ is a $g$ semi-open map.

3.19 Definition A function $\mathrm{q}:(X, \mathrm{gx}) \rightarrow\left(X^{\prime}, \mathrm{gx}^{\prime}\right)$ is said to be perfectly $\mathrm{g}$ - $\beta$-irresolute if $\mathrm{q}^{-1}(\mathrm{~V})$ is g-clopen in $\mathrm{X}$ for every g- $\quad \beta$-open set $\mathrm{V}$ of $\mathrm{X}^{\prime}$.

3.20 Example Let $X=\{x, y, z\}$ with the generalized topology $\mathrm{gx}=\{\varnothing, \mathrm{X},\{\mathrm{x}\},\{\mathrm{x}, \mathrm{y}\},\{\mathrm{x}, \mathrm{z}\},\{\mathrm{y}, \mathrm{z}\}\}$ and $\mathrm{X}^{\prime}=\{\mathrm{a}$, $b, c\}$ with the generalized topology $g x^{\prime}=\left\{\varnothing, X^{\prime},\{a\}\right.$.

We define a mapping $\mathrm{q}:(\mathrm{X}, \mathrm{gx}) \rightarrow\left(\mathrm{X}^{\prime}, \mathrm{gx}\right)$ such that $\mathrm{q}(\mathrm{x})=\mathrm{b}$ and $\mathrm{q}(\mathrm{y})=\mathrm{q}(\mathrm{z})=\mathrm{a}$. It can be easily checked that the pre-images of every g- $\beta$-open sets $\{a\},\{a, b\},\{a, c\}$ of $X^{\prime}$ are $\{y, z\}, X,\{y, z\}$, which are g-clopen in $X$, hence $q$ is perfectly g- irresolute.

3.21 Definition A function $\mathrm{q}:(X, \mathrm{gx}) \rightarrow\left(\mathrm{X}^{\prime}, \mathrm{gx}^{\prime}\right)$ is called perfectly g-continuous if $\mathrm{q}^{-1}(\mathrm{~V})$ is $\mathrm{g}$-clopen in $\mathrm{X}$ for every g- open set V of $\mathrm{X}^{\prime}$.

3.22 Example Refer Example 3.20 in which only g-open sets of $X^{\prime}$ are $\{a\}, \emptyset, X$ and their respective pre-images are $\{\mathrm{x}\}, \quad \emptyset, \mathrm{X}$, which are $\mathrm{g}$-clopen in X. Hence, $\mathrm{q}$ is perfectly g- continuous.

3.23 Definition A function $q:(X, g x) \rightarrow\left(X^{\prime}, g^{\prime}\right)$ is said to be perfectly g-irresolute if $\mathrm{q}^{-1}(\mathrm{~V})$ is g-clopen in $\mathrm{X}$ for every g-semi-open set $\mathrm{V}$ of $\mathrm{X}^{\prime}$.

3.24 Example Let $X=\{a, b, c\}$ with the generalized topology $\operatorname{gx}=\{\varnothing, X,\{a\},\{a, b\},\{a, c\},\{b, c\}\}\}$ and $X^{\prime}=\{1$, $2,3\}$ with the topology $\operatorname{gx}^{\prime}=\{\varnothing,\{2,3\}\}$.

We define a mapping $\mathrm{q}:(\mathrm{X}, \mathrm{gx}) \rightarrow\left(\mathrm{X}^{\prime}, \mathrm{gx}^{\prime}\right)$ such that $\mathrm{q}(\mathrm{a})=1, \mathrm{q}(\mathrm{b})=2$ and $\mathrm{q}(\mathrm{c})=3$. It may be easily check that the only g-semi-open sets of $X^{\prime}$ are $\{2,3\},\{1\}, \emptyset, X^{\prime}$ and their respective pre-images are $\{b, c\},\{a\}, \emptyset, X$, which are $g$ clopen in $\mathrm{X}$. Hence, q is completely g-irresolute.

3.25 Definition A function $q:(X, g x) \rightarrow\left(X^{\prime}, g x^{\prime}\right)$ is called completely g-irresolute if $q^{-1}(\mathrm{~V})$ is gr-open in $\mathrm{X}$ for every g- semi - open set V of $X^{\prime}$.

3.26 Example Let $X=\{a, b, c\}$ with the generalized topology $\mathrm{gx}=\{\phi, X,\{\mathrm{a}\},\{\mathrm{b}, \mathrm{c}\},\{\mathrm{a}, \mathrm{c}\}\}$ and $\mathrm{X}^{\prime}=\{1,2,3\}$ with the topology $\mathrm{gx}^{\prime}=\{\phi,\{2,3\}\}$. 
We define a mapping q: $(X, g x)\left(X^{\prime}, g x^{\prime}\right)$ such that $q(a)=1$, $q(b)=2, q(c)=3$. It may be easily check that the only g-semiopen sets of $X^{\prime}$ are $\{2,3\},\{1\}, \varnothing$ and their respective preimages are $\{b, c\},\{a\}, \emptyset$, which are gr-open in $X$. Hence, $q$ is completely g-irresolute.

3.27 Definition A function $\mathrm{q}:(\mathrm{X}, \mathrm{gx}) \rightarrow\left(\mathrm{X}^{\prime}, \mathrm{gx}^{\prime}\right)$ is called completely g-preirresolute if $\mathrm{q}^{-1}(\mathrm{~V})$ is gr-open in $\mathrm{X}$ for every g-pre -open set $\mathrm{V}$ of $\mathrm{X}^{\prime}$.

3.28 Example Let $X=\{a, b, c\}$ with the generalized topology $g x=\{\phi,\{a\},\{b\},\{a, b\}\}$ and $X^{\prime}=\{1,2,3\}$ with the generalized topology $\operatorname{gx}^{\prime}=\{\emptyset,\{2,3\}\}$.

We define a mapping $\mathrm{q}:(\mathrm{X}, \mathrm{gx}) \rightarrow\left(\mathrm{X}^{\prime}, \mathrm{gx}^{\prime}\right)$ such that $q(a)=3, q(b)=2, q(c)=1$. It may be easily check that the only g-pre-open sets of $X^{\prime}$ are $\{2\},\{3\},\{2,3\}, \varnothing$ and their respective pre-images are $\{b\},\{a\},\{a, b\}, \emptyset$, which are gropen in X. Hence, q is completely g-preirresolute.

3.29 Definition A function $\mathrm{q}:(X, \mathrm{gx}) \rightarrow\left(X^{\prime}, \mathrm{gx}^{\prime}\right)$ is called completely $\mathrm{g}$ - $\alpha$-irresolute if $\mathrm{q}^{-1}(\mathrm{~V})$ is gr-open in $\mathrm{X}$ for every $\mathrm{g}$ - $\alpha$-open set $\mathrm{V}$ of $\mathrm{X}^{\prime}$.

3.30 Example Let $X=\{a, b, c\}$ with the generalized topology $\mathrm{gx}=\{\varnothing,\{b\},\{c\},\{b, c\}\}$ and $X^{\prime}=\{1,2,3\}$ with the generalized topology $\operatorname{gx}^{\prime}=\{\varnothing,\{2,3\}\}$.

We define a mapping $\mathrm{q}:(\mathrm{X}, \mathrm{gx}) \rightarrow\left(\mathrm{X}^{\prime}, \mathrm{gx}^{\prime}\right)$ such that $q(a)=1, q(b)=2$ and $q(c)=3$. It may be easily check that the only g- $\alpha$-open sets of $X^{\prime}$ are $\{2,3\}, \varnothing$ and their respective preimages are $\{b, c\}, \varnothing$, which are gr-open in $X$. Hence, $q$ is completely g- $\alpha$-irresolute.

3.31 Definition A function $\mathrm{q}:(\mathrm{X}, \mathrm{gx}) \rightarrow\left(\mathrm{X}^{\prime}, \mathrm{gx}^{\prime}\right)$ is called strongly $\mathrm{g}$ - $\beta$-irresolute if $\mathrm{q}^{-1}(\mathrm{~V})$ is g-open in $\mathrm{X}$ for every g- $\beta$-open set $\mathrm{V}$ of $\mathrm{X}^{\prime}$.

3.32 Example Let $X=\{a, b, c\}$ with the generalized topology gx $=\{\varnothing, X,\{a\},\{a, b\},\{a, c\},\{b, c\}\}\}$ and $X^{\prime}=\{1$, $2,3\}$ with the generalized topology $\mathrm{gx}^{\prime}=\left\{\varnothing, \mathrm{X}^{\prime},\{1\}\right\}$.

We define a mapping $\mathrm{q}:(\mathrm{X}, \mathrm{gx}) \rightarrow\left(\mathrm{X}^{\prime}, \mathrm{gx} \mathrm{X}^{\prime}\right)$ such that $q(a)=1, q(b)=2$ and $q(c)=3$. It may be easily check that the only $\mathrm{g}$ - $\beta$-open sets of $\mathrm{X}^{\prime}$ are $\{1\},\{1,2\},\{1,3\}, \varnothing, X^{\prime}$ and their respective pre-images are $\{a\},\{a, b\},\{a, c\}, \varnothing, X$, which are $g$-open in $X$. Hence, $q$ is strongly $g$ - $\beta$-irresolute.

3.33 Definition A function $\mathrm{q}:(X, \mathrm{gx}) \rightarrow\left(X^{\prime}, \mathrm{gx}^{\prime}\right)$ is called strongly g-M-precontinuous if $\mathrm{q}^{-1}(\mathrm{~V})$ is g-open in $\mathrm{X}$ for every $\mathrm{g}$ - pre -open set $\mathrm{V}$ of $\mathrm{X}^{\prime}$.

3.34 Example Let $X=\{a, b, c\}$ with the generalized topology gx $=\{\varnothing,\{a\},\{b\},\{a, b\}\}$ and $X^{\prime}=\{1,2,3\}$ with the generalized topology $\mathrm{gx}^{\prime}=\{\emptyset,\{1,2\}\}$.

We define a mapping $\mathrm{q}: \mathrm{X} \rightarrow \mathrm{Y}$ such that $\mathrm{q}(\mathrm{a})=1$, $q(b)=2$, and $q(c)=3$. It may be easily check that the only gpre -open sets of $X^{\prime}$ are $\{1\},\{2\},\{1,2\}, \varnothing$ and their respective pre-images are $\{a\},\{b\},\{a, b\}, \emptyset$, which are gopen in $\mathrm{X}$. Hence, $\mathrm{q}$ is strongly $\mathrm{g}-\mathrm{M}$-precontinuous.

3.35 Definition A function $\mathrm{q}:(X, \mathrm{gx}) \rightarrow\left(X^{\prime}, \mathrm{gx}^{\prime}\right)$ is called strongly $g$ - $\alpha$-irresolute if $q^{-1}(V)$ is $g$ - open in $X$ for every g- $\alpha$-open set $\mathrm{V}$ of $\mathrm{X}^{\prime}$.

3.36 Example Let $X=\{a, b, c\}$ with the generalized topology $\operatorname{gx}=\{\varnothing, X,\{a, b\},\{b, c\}\}\}$ and $X^{\prime}=\{1,2,3\}$ with the generalized topology $\mathrm{gx}^{\prime}=\{\varnothing,\{2,3\}\}$.
We define a mapping $\mathrm{q}:(\mathrm{X}, \mathrm{gx}) \rightarrow\left(\mathrm{X}^{\prime}, \mathrm{gx}^{\prime}\right)$ such that $q(a)=1, q(b)=2$ and $q(c)=3$. It may be easily check that the only $g$ - $\alpha$-open set of $X^{\prime}$ are $\{2,3\}, \emptyset$ and their respective preimages are $\{b, c\}, \emptyset$, which are g-open in $X$. Hence, $q$ is strongly $g-\alpha$-irresolute.

3.37 Definition A function $\mathrm{q}:(\mathrm{X}, \mathrm{gx}) \rightarrow\left(\mathrm{X}^{\prime}, \mathrm{gx}^{\prime}\right)$ is called perfectly $g$ - $\alpha$-irresolute if $q^{-1}(V)$ is $g$-clopen in $X$ for every g- $\alpha$-open set $\mathrm{V}$ of $\mathrm{X}^{\prime}$.

3.38 Example Let $X=\{a, b, c\}$ with the generalized topology $\mathrm{gx}=\{\varnothing, X,\{b\},\{a, b\},\{a, c\}\}\}$ and $X^{\prime}=\{1,2,3\}$ with the generalized topology $\mathrm{gx}^{\prime}=\{\varnothing,\{1,3\}\}$.

We define a mapping $\mathrm{q}: \mathrm{X} \rightarrow \mathrm{Y}$ such that $\mathrm{q}(\mathrm{a})=1$, $q(b)=2$ and $q(c)=3$. It may be easily check that the only $g-\alpha-$ open sets of $X^{\prime}$ are $\{1,3\}, \emptyset$ and their respective pre-images are $\{a, c\}, \varnothing$, which are g-clopen in X. Therefore, $q$ perfectly g- $\alpha$ - irresolute.

3.39 Remark From the Definitions 3.1-3.38 and Remark 2.3, we have the following relations:

$$
\begin{array}{ll} 
& \Rightarrow \mathrm{g} \text { - } \beta \text {-irresolute } \\
& \Rightarrow \mathrm{g} \text { - } \beta \text {-continuous } \\
\text { Strongly g- } \beta \text { - irresolute } \quad & \text { g-irresolute } \\
& \Rightarrow \mathrm{g} \text {-semi-continuous } \\
& \Rightarrow \text { strongly g-M-precontinuous } \\
& \Rightarrow \text { strongly g- } \alpha \text {-irresolutes } \\
& \Rightarrow \text { completely g- } \beta \text {-irresolute } \\
& \Rightarrow \text { completely g-continuous } \\
& \Rightarrow \text { perfectly g-continuous } \\
& \Rightarrow \text { perfectly g-irresolute } \\
& \Rightarrow \text { completely g-irresolute } \\
& \Rightarrow \text { completely g-preirresolute } \\
& \Rightarrow \text { completely g- } \alpha \text {-irresolute } \\
& \Rightarrow \text { perfectly g- } \alpha \text {-irresolute }
\end{array}
$$

\section{STUDY OF g-CONTINUOUS FUNCTIONS IN FINE SPACE}

The following result plays a key role in investigating certain interesting properties of g-continuous functions in fine space which were defined earlier (cf. Definition 3.1-3.38). It has been noted earlier that, a fine space is a special case of generalized topology. Moreover, the mappings which were defined in generalized topology can be defined in a more compact manner in case of fine space.

4.1 Theorem In the fine space each fine-open set is
(i) g-semi-open
(ii) $g$ - $\alpha$-open
(iii) g-pre- open
(iv) g- $\beta$-open. 


\section{Proof}

Let $\left(X, \tau, \tau_{f}\right)$ be the fine space. Let $S \subset X$ and $S$ in $\tau_{\mathrm{f}}$

Case 1. If $S$ is both g-open and g-closed then, $i_{g}(S)=c_{g}(S)=$ $\mathrm{S}$ and hence (i), (ii), (iii) and (iv) follows directly.

Case 2. $S \in \tau_{\mathrm{f}}$ but $\mathrm{S}$ is not both g-open and g-closed.

(i) We first show that $\mathrm{S}$ is g-semi-open.

Since, $S \in \tau_{\mathrm{f}}$, we have

$$
\mathrm{S}=\mathrm{i}_{\mathrm{g}}(\mathrm{S})
$$

By the Definition 2.4, we have

$$
\mathrm{S} \subseteq \mathrm{c}_{\mathrm{g}}(\mathrm{S})
$$

Using (4.1) and (4.2), we get

$$
\mathrm{S} \subseteq \mathrm{c}_{\mathrm{g}}\left(\mathrm{i}_{\mathrm{g}}(\mathrm{S})\right)
$$

Thus, $\mathrm{S}$ is g-semi-open.

(ii) We next show that $\mathrm{S}$ is $\mathrm{g}-\alpha$-open.

It is well known that $\mathrm{A} \subseteq \mathrm{B} \Rightarrow \mathrm{i}_{\mathrm{g}}(\mathrm{A}) \subseteq \mathrm{i}_{\mathrm{g}}(\mathrm{B})$. Applying this property of interior in (4.3), we get

$$
\mathrm{i}_{\mathrm{g}}(\mathrm{S}) \subseteq \mathrm{i}_{\mathrm{g}}\left(\mathrm{c}_{\mathrm{g}}\left(\mathrm{i}_{\mathrm{g}}(\mathrm{S})\right)\right)
$$

Thus, $\mathrm{S}$ is $\mathrm{g}-\alpha$-open, when we appeal to (4.1).

(iii) We show that $\mathrm{S}$ is g-pre-open.

Since, $S \in \tau_{\mathrm{f}}$, by using (4.1) and (4.2), we get

$$
\mathrm{S}=\mathrm{i}_{\mathrm{g}}(\mathrm{S}) \subseteq \mathrm{i}_{\mathrm{g}}\left(\mathrm{c}_{\mathrm{g}}(\mathrm{S})\right)
$$

Thus, $\mathrm{S}$ is g-pre-open.

(iv) We next show that $S$ is $g-\beta$-open.

We know that if $\mathrm{A} \subseteq \mathrm{B} \Rightarrow \mathrm{c}_{\mathrm{g}}(\mathrm{A}) \subseteq \mathrm{c}_{\mathrm{g}}(\mathrm{B})$. Applying this property of closure in (4.5), we have

$$
\mathrm{c}_{\mathrm{g}}(\mathrm{S}) \subseteq \mathrm{c}_{\mathrm{g}}\left(\mathrm{i}_{\mathrm{g}}\left(\mathrm{c}_{\mathrm{g}}(\mathrm{S})\right)\right)
$$

From (4.2) and (4.6) we have,

$$
\mathrm{S} \subseteq \mathrm{c}_{\mathrm{g}}\left(\mathrm{i}_{\mathrm{g}}\left(\mathrm{c}_{\mathrm{g}}(\mathrm{S})\right)\right)
$$

Thus, $\mathrm{S}$ is $\mathrm{g}-\beta$-open.

Hence, we finally conclude that every $\mathrm{S} \in \tau_{\mathrm{f}}$ is $\mathrm{g}$ semi-open, g- $\alpha$-open, g-pre-open and g- $\beta$-open.

In view of Theorem 4.1, we illustrate the following example.

4.2 Example Let $X=\{a, b, c\}$ be a topological space with the topology $\tau=\{\varnothing, X,\{a\},\{b\},\{a, b\}\}$ then, $\tau_{f}=\{\varnothing$, $X, \quad\{a\},\{b\},\{a, b\},\{a, c\},\{b, c\}\}, F_{f}=\{\varnothing, X,\{b, c\},\{a$, $c\},\{c\}, \quad\{b\},\{a\}\}$.

Let $\mathrm{A}=\{\mathrm{a}\}$, consider $\mathrm{i}_{\mathrm{g}}\left(\mathrm{c}_{\mathrm{g}}\left(\mathrm{i}_{\mathrm{g}}(\mathrm{A})\right)\right)=\{\mathrm{a}\} \Rightarrow \mathrm{A}$ is $\mathrm{g}$ - $\alpha$-open Again, consider $\mathrm{c}_{\mathrm{g}}\left(\mathrm{i}_{\mathrm{g}}\left(\mathrm{c}_{\mathrm{g}}(\mathrm{A})\right)\right)=\{\mathrm{a}\} \Rightarrow \mathrm{A}$ is $\mathrm{g}$ - $\beta$-open. We may easily check that A is g-pre- open, g-semi-open. Similarly we may check that all fine-open sets are satisfying the conditions of g-semi-open, g-pre-open, g- $\alpha$-open and g- $\beta$ ospen sets.

4.3 Definition Let $\left(X, \tau_{\mathrm{f}}\right)$ and $\left(\mathrm{Y}, \tau_{\mathrm{f}}{ }^{\prime}\right)$ be a fine space. Then, a map $\mathrm{r}:\left(\mathrm{X}, \tau_{\mathrm{f}}\right) \rightarrow\left(\mathrm{Y}, \tau_{\mathrm{f}}{ }^{\prime}\right)$ is said to be f-clopen (resp. fine-regular) continuity if $\mathrm{r}^{-1}(\mathrm{~V})$ is f-clopen (resp. regular fine open) in $\mathrm{X}$ for every $\mathrm{f}$-clopen (resp. fine-regular open) set $\mathrm{V}$ of $\mathrm{Y}$.

4.4 Example Let $X=\{a, b, c\}$ with the topology $\tau=$ $\{\varnothing, X,\{a\},\{a, b\}\}, \tau_{f}=\{\varnothing, X,\{a\},\{a, b\},\{a, c\},\{b\},\{b$, c $\}$ and $Y=\{1,2,3\}$ with the topology $\tau^{\prime}=\{\varnothing, Y,\{1,2\}\}$, $\tau_{\mathrm{f}}^{\prime}=\{\emptyset, \mathrm{Y},\{1\},\{1,2\},\{1,3\},\{2\},\{2,3\}$.

We define a mapping $\mathrm{r}: \mathrm{X} \rightarrow \mathrm{Y}$ such that $\mathrm{r}(\mathrm{a})=$ 1, $\quad r(b)=2$ and $r(c)=3$. It may be checked that the preimages of f-clopen sets $\{1\},\{1,2\},\{1,3\},\{2\},\{2,3\}$ of $Y$ are $\{a\},\{a, b\},\{a, c\},\{b\},\{b, c\}$ respectively, which are $f-$ clopen in X. Therefore, $\mathrm{r}$ is f-clopen map.

4.5 Remark By Theorem 4.1 and Definition 2.10, we note that the following relations hold:

$$
\begin{aligned}
& \Rightarrow \mathrm{g} \text { - } \beta \text {-irresolute } \\
& \Rightarrow \mathrm{g} \text { - } \beta \text {-continuous } \\
\text { Fine-irresolute } \quad & \mathrm{g} \text {-irresolute } \\
& \Rightarrow \mathrm{g} \text {-semi-continuous } \\
& \Rightarrow \text { strongly g- } \beta \text {-irresolute } \\
& \Rightarrow \text { strongly g-M-precontinuous } \\
& \Rightarrow \text { strongly g- } \alpha \text {-irresolutes }
\end{aligned}
$$

In the following example, we would like to elaborate our above claim (cf. Remark 4.5).

4.6 Example Let $X=\{a, b, c\}$ with the topology $\tau=\{$ $\emptyset, X,\{a\},\{b\},\{a, b\}\}, \tau_{\mathrm{f}}=\{\varnothing, X,\{a\},\{a, b\},\{a, c\},\{b\},\{b$, c $\}\}$ and $Y=\{1,2,3\}$ with the topology $\tau^{\prime}=\{\varnothing, Y,\{1,2\}\}, \tau$ ${ }_{\mathrm{f}}^{\prime}=\{\varnothing, \quad\{1\},\{1,2\},\{1,3\},\{2\},\{2,3\}\}$.

We define a mapping $\mathrm{r}: \mathrm{X} \rightarrow \mathrm{Y}$ such that $\mathrm{r}(\mathrm{a})=1$, $r(b)=2$ and $r(c)=3$. It may be checked that the pre-images of fine-open sets (resp. g- $\beta$-open, g-open, g-semi-open, g-open, g-pre-open, g- $\alpha$-open) $\{1\},\{1,2\},\{1,3\},\{2\},\{2,3\}$ of $Y$ are $\{a\},\{a, b\},\{a, c\},\{b\},\{b, c\}$, which are fine-open (resp. g- $\quad \beta$-open, g- $\beta$-open, g-semi-open, g-semi-open, gopen, $g$-open) in $X$, therefore $r$ is fine-irresolute (resp. g- $\beta$ irresolute, $\mathrm{g}-\beta$-continuous, $\mathrm{g}$-irresolute, $\mathrm{g}$-semi-continuous, strongly g-M- precontinuous, strongly g- $\alpha$-irresolute).

4.7 Definition A function $r:\left(X, \tau_{f}\right) \rightarrow\left(Y, \tau_{f}^{\prime}\right)$ is said to be completely fine-irresolute if $\mathrm{r}^{-1}(\mathrm{~V})$ is $\mathrm{fr}$-open or f-clopen in $\mathrm{X}$ for every fine open set $\mathrm{V}$ of $\mathrm{Y}$.

4.8 Remark By Theorem 4.1, Definition 4.3 and Remark 2.7, we note that the following relations hold:

$$
\begin{aligned}
& \Rightarrow \text { completely g-continuous } \\
& \Rightarrow \text { g-R-map } \\
& \Rightarrow \text { completely g-irresolute } \\
& \Rightarrow \text { completely g-pre-irresolute } \\
& \Rightarrow \text { perfectly g-irresolute }
\end{aligned}
$$


Completely fine-irresolute $\Rightarrow$ perfectly g-continuous

$$
\begin{aligned}
& \Rightarrow \text { completely g- } \beta \text {-irresolute } \\
& \Rightarrow \text { completely g- } \alpha \text {-irresolute } \\
& \Rightarrow \text { perfectly g- } \alpha \text {-irresolute } \\
& \Rightarrow \text { perfectly g- } \beta \text {-irresolute }
\end{aligned}
$$

4.9 Example Let $X=\{a, b, c\}$ with the topology $\tau=\{\varnothing$, $X,\{a\},\{b\},\{a, b\},\{b, c\}\}, \tau_{f}=\{\varnothing, X,\{a\},\{a, b\},\{a, c\}$, $\{b\}, \quad\{b, c\},\{c\}\}$ and $Y=\{1,2,3\}$ with the topology $\tau{ }^{\prime}=$ $\{\varnothing, \mathrm{Y}, \quad\{1,2\}\}, \tau_{\mathrm{f}}^{\prime}=\{\varnothing, \mathrm{Y},\{1\},\{1,2\},\{2\},\{2,3\}\},\{1$, $3\}$.

We define a mapping $\quad \mathrm{r}: \mathrm{X} \rightarrow \mathrm{Y}$ such that $\mathrm{r}(\mathrm{a})=1$, $r(b)=2$ and $r(c)=3$. It may be checked that the pre-images of fine-open (resp. g-open, gr-open, g-semi-open, g-pre-open, gsemi-open, g-open, g- $\beta$-open, g- $\alpha$-open, g- $\alpha$-open, g- $\beta$-open) sets of $Y$ viz. $\{1\},\{1,2\},\{2\},\{2,3\}\},\{1,3\}$ are $\{a\},\{a, b\}$, $\{b\},\{b, c\}\},\{a, c\}$ respectively, which are fr-open (resp. gropen, gr-open, gr-open, gr-open, g-clopen, g-clopen, gr-open, gr-open, g-clopen, g-clopen) in $\mathrm{X}$. Therefore, $\mathrm{r}$ is completely fine-irresolute (resp. completely g-continuous, gR-map, completely g-irresolute, completely g-preirresolute, perfectly g-irresolute, perfectly g-continuous, completely g$\beta$-irresolute, completely $g$ - $\alpha$-irresolute, perfectly $g-\beta$ irresolute, perfectly g- $\quad \beta$ - irresolute) map.

\section{CONCLUSION}

The concept of homeomorphism is required in quantum physics. There may be some situations under which a topology may not be defined. In that case, we may define a generalized topological space and use the concept of generalized homeomorphism.

\section{ACKNOWLEDGEMENT}

The authors would like to thank University Grants Commission for financial support under its major research project scheme.

\section{REFERENCE}

[1] Abd El-Monsef, M. E., Mahmoud R. A., El-Deeb, S. N. $\beta$-open sets and $\beta$-continuous mappings, Bull Fac Sci Assiut Univ, 1983, 12(1), 77-90.

[2] Abd El-Monsef, M. E., Mahmoud, R. A., Nasef A. A., , A class of functions stronger than M--precontinuity, preirresolute and A-functions, qatar Univ Sci Bull, 1990, 10, 41-8.
[3] Arya, S. P., Gupta, R., On strongly continuous mappings, Kyungpook Math. J, 1974, 14, 131-43.

[4] Beceren, Y., Almost $\alpha$-irresolute functions, Bull. Calcutta Math. Soc., 92(2000), 213-218.

[5] Biswas N., Some mappings in topological spaces, Bull Cal Math Soc, 1969,61, 127-35.

[6] Carnaham, D., Some properties related to compacteness in topological spaces, $\mathrm{Ph}$. D. thesis, University of Arkansas, 1973.

[7] Crossley, S. G., Hildebrand S. K., Semi-topological properties, Fund Math, 1972, 74, 233-54.

[8] Császár, A., Generalized topology, generalized continuity, Acta Math. Hungar., 96(2002), 351-357 .

[9] Császár, A., Generalized open sets in generalized topologies, Acta Math. Hungar., 106(2005), 53-66.

[10] Levin, N., Semi-open sets and semi-continuity in topological spaces, Am Math Mon, 1963, 70, 36-41.

[11] Lo Faro, G., On strongly $\alpha$-irresolute mappings, Ind J Pure Appl Math, 1987, 2(18), 146-51.

[12] Mahmoud, R. A., Abd El-Monsef, M. E., $\beta$ - irresolute and $\beta$-topological invarient, Proc Pakistan Acad Sci, 1990, 27, 285-96.

[13] Min, W. K., Almost continuity on generalized topological spaces, Acta Math Hungar, 125, 2009, 121125 .

[14] Nasef, A. A., Noiri, T., Strongly $\beta$-irresolute functions, J Nat Sci Math, 1996, 36, 199-206.

[15] Navalagi, G. B., Completely preirresolute functions and completely gp-irresolute functions, Topology atlas preprint, 2001.

[16] Navalagi, G. B., On completely $\alpha$-irresolute functions, Topology atlas preprint, 2001.

[17] Noiri, T., Super continuity and some strong forms of continuity, Ind J Pure Appl Math, 1984, 15(3), 241-50.

[18] Powar, P. L., Rajak, K., Fine-irresolute Mappings, (Communicated)

[19] Powar P. L., Rajak, K., Study of g- $\alpha$-irresolute functions in the special class of generalized topological space, IJCA, 31, 8, 2011.

[20] Zorlutuna, I., On strong forms of completely irresolute functions, Chaos, Solitons and Fractals, 38(2008), 970979 . 